\title{
Dendritic Localization of the Translational Repressor Pumilio 2 and Its Contribution to Dendritic Stress Granules
}

\author{
John P. Vessey, ${ }^{1}$ Angelo Vaccani, ${ }^{1,2}$ Y unli Xie, ${ }^{1}$ Ralf Dahm, ${ }^{1}$ Daniela Karra, ${ }^{1}$ Michael A. Kiebler, ${ }^{1}$ and Paolo Macchi ${ }^{1}$ \\ ${ }^{1}$ Division of Neural Cell Biology, Center for Brain Research, Medical University of Vienna, A-1090 Vienna, Austria, and ${ }^{2}$ Department of Structural and \\ Functional Biology, Pharmacology Section, Center of Neurosciences, University of Insubria, 21052 Busto Arsizio (VA), Italy
}

\begin{abstract}
Pumilio (Pum) protein acts as a translational inhibitor in several organisms including yeast, Drosophila, Xenopus, and mammals. Two Pumilio genes, Pum 1 and Pum2, have been identified in mammals, but their function in neurons has not been identified. In this study, we found that Pum $2 \mathrm{mRNA}$ is expressed during neuronal development and that the protein is found in discrete particles in both the cell body and the dendritic compartment of fully polarized neurons. This finding indicates that Pum2 is a novel candidate of dendritically localized ribonucleoparticles (RNPs). During metabolic stress, Pum2 is present in stress granules (SGs), which are subsequently detected in the somatodendritic domain. It remains excluded from processing bodies under all conditions. When overexpressed in neurons and fibroblasts, Pum2 induces the formation of SGs that also contain T-cell intracellular antigen 1 (TIA-1)-related protein, eukaryotic initiation factor 4E, poly(A)-binding protein, TIA-1, and other RNA-binding proteins including Staufen1 and Barentsz. This induction of SGs is dependent on the RNA-binding domain and a glutamine-rich region in the $\mathrm{N}$ terminus of Pum2. This glutamine-rich region behaves in a similar manner as TIA-1 and prion protein, two molecules with known roles in protein aggregation. Pum2 downregulation in neurons via RNA interference (RNAi) interferes with the formation of SGs during metabolic stress. Cotransfection with an RNAi-resistant portion of the Pum 2 mRNA restores SG formation. These results suggest a role for Pum2 in dendritic RNPs and SG formation in mammalian neurons.
\end{abstract}

Key words: Pumilio 2; dendrite; stress granule; hippocampal neurons; RNA-binding proteins; ribonucleoparticles

\section{Introduction}

In Drosophila, Pumilio (Pum) functions as a translational repressor in oocytes and embryos (Micklem, 1995). The role of the Pum protein is to sustain the mitotic proliferation of stem cells, control cell development, and modulate fate specification and differentiation (Murata and Wharton, 1995; Asaoka-Taguchi et al., 1999). Drosophila Pum and its homolog in Caenorhabditis elegans, fem-3 binding factor, are founding members of a group of RNAbinding proteins known as the PuF family and are involved in translational inhibition via a conserved characteristic C-terminal domain (Wickens et al., 2002). This domain contains eight tandem repeats and binds RNA through a defined nucleotide sequence motif termed the nanos responsive element (NRE), located in the $3^{\prime}$-untranslated region (3'-UTR) of target mRNAs (Wharton and Struhl, 1991; Zamore et al., 1997). An example of

Received Feb. 14, 2006; revised April 5, 2006; accepted May 3, 2006.

This work was supported by the Sonderforschungsbereich (SFB446), Hertie-Stiftung, Schram-Stiftung, a Human Frontier Science Program network, and an initial start-up by the Medizinische Universität Wien (all to M.A.K.). We thank Dr. Eric Arn and Fabian Tübing for helpful comments on this manuscript. We also thank Dr. Anna Villa (Consiglio Nazionale delle Ricerche-Istituto di Tecnologie Biomediche, Milano) for providing the Northern blot and Sabine Thomas and Martina Schwarz for technical assistance. Dep1a-GFP plasmid was kindly provided by Dr. J. Lykke-Andersen (University of Colorado), CPEB-GFP and Maskin-CFP plasmids by Dr. J. Richter (University of Massachusetts Medical School), and the Lsm1 antibody by Dr. R. Lührmann (MPI, Göttingen, Germany).

Correspondence should be addressed to Paolo Macchi, Division of Neuronal Cell Biology, Center for Brain Research, Medical University of Vienna, Spitalgasse 4, A-1090 Vienna, Austria. E-mail: paolo.macchi@ meduniwien.ac.at.

DOI:10.1523/JNEUROSCI.0649-06.2006

Copyright $\odot 2006$ Society for Neuroscience $\quad$ 0270-6474/06/266496-13\$15.00/0 this interaction occurs when Pum binds the NRE in the $c y c l i n-B$ mRNA of the Xenopus oocyte and inhibits translation causing the arrest of oocyte maturation (Nakahata et al., 2001, 2003).

Indications that Pum may have a significant role in the nervous system come from studies performed in Drosophila. First, via translational control mechanisms, Pum modulates dendrite morphogenesis in peripheral neurons (Ye et al., 2004). Second, Pum influences synaptic growth and function by regulating expression of eukaryotic initiation factor $4 E$ (eIF4E) $\mathrm{mRNA}$ at the Drosophila neuromuscular junction (Menon et al., 2004). Third, by modulating expression of a voltage-gated sodium channel, Pum controls neuronal excitability (Schweers et al., 2002; Mee et al., 2004). Finally, Dubnau et al. (2003) demonstrated that Drosophila Pum and Staufen (Stau) are regulated at the transcriptional level during memory formation, suggesting involvement of these proteins in long-term memory.

Mammals express two Pum genes, Pum 1 and Pum2, encoding proteins with high homology to Drosophila Pum (Spassov and Jurecic, 2002). Several mRNAs associated with mammalian Pum2 have been identified using a three-hybrid screen (Fox et al., 2005). Some transcripts encode proteins that are important in neurons, including the amyloid $\beta$ precursor, and the elongation factor $1 \mathrm{~A}$, an mRNA that is found in dendrites of hippocampal neurons and that undergoes local translation (Tsokas et al., 2005). Because Pum acts as a repressor of RNA translation in yeast, Drosophila, and Xenopus, it also represents a good candidate component of dendritic ribonucleoparticles (RNPs) because 
A

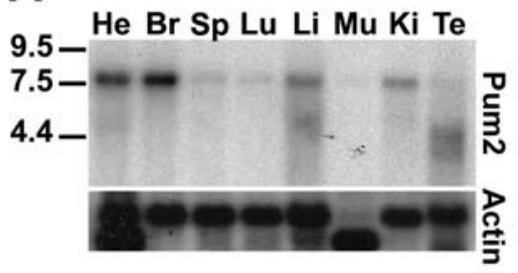

B
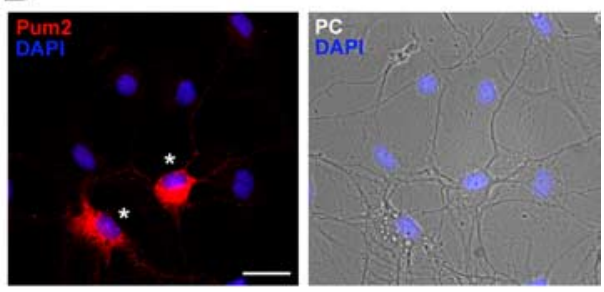

C
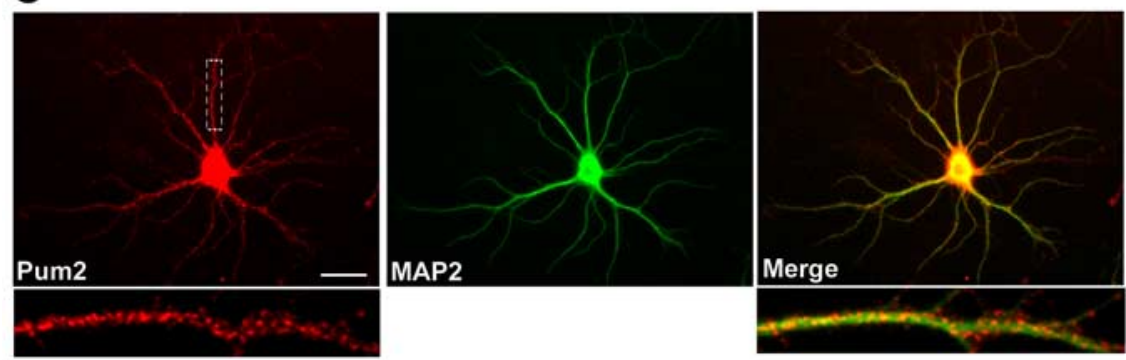

D
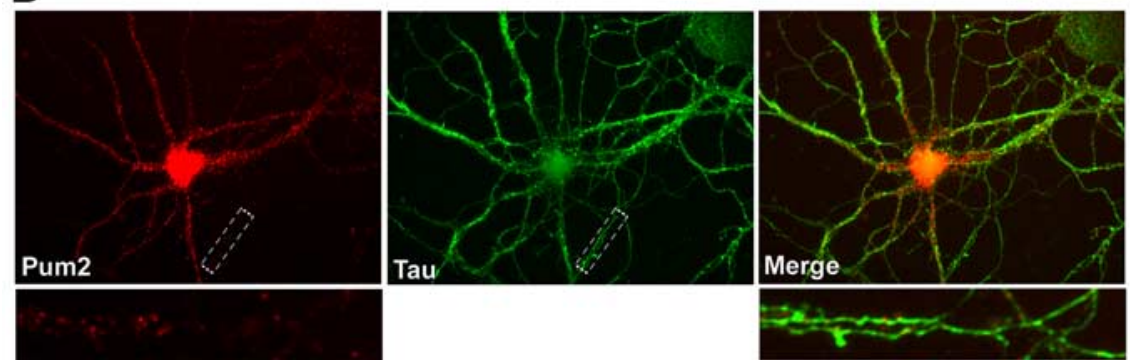

Figure 1. Subcellular localization of Pum2 in mature hippocampal neurons. $A$, Northern blot of Pum2 mRNA expression in mouse tissues. Significant expression was found in heart (He) and brain (Br) with minor expression in liver (Li) and kidney (Ki). Pum2 was detected in testis (Te), but with multiple bands at a lower size than expected. Sp, Spleen; Lu, lung; Mu, skeletal muscle. $\boldsymbol{B}$, Fifteen DIV primary cultures of hippocampal neurons stained with anti-Pum2 antibodies demonstrate that Pum 2 is expressed in neurons (indicated with asterisks) and not significantly expressed by glial cells. PC, Phase contrast image; DAPI, 4',6' diamidino-2-phenylindole. C, D, Pum2 localizes within the dendritic compartment. Immunostaining of mature hippocampal neurons shows that Pum2 (red) forms discrete particles along dendrites stained with MAP2 (green). Few Pum2 particles can be detected in the processes positive for Tau (green, enlargement). Scale bars, $10 \mu \mathrm{m}$.

RNP transport and translational silencing are thought to occur simultaneously (Dahm and Kiebler, 2005).

Recently, RNA-binding proteins such as fragile X mental retardation protein (FMRP), Staufen, and Smaug, which are involved in dendritic mRNA localization and translation, have been found to accumulate in stress granules (SGs) (Mazroui et al., 2002; Baez and Boccaccio, 2005; Thomas et al., 2005; Kim et al., 2006). This process occurs when cells are exposed to environmental stresses. These structures contain mRNAs, the translation of which has been temporarily silenced (Kedersha and Anderson, 2002). Here, we characterize Pum 2 expression and function in mammalian hippocampal neurons. During stress, Pum2 is recruited into somatodendritic SGs of mature hippocampal neurons. It is, however, excluded from processing bodies (P-bodies). We also identify domains within Pum 2 that are responsible for SG formation and show that loss of Pum 2 impedes the formation of SGs in hippocampal neurons.

\section{Materials and Methods}

Cell cultures, transient transfections, and Western blotting. Rat hippocampal neurons were cultured and transiently transfected as described by
Goetze et al. (2004). HeLa and COS cells were cultured as described by Macchi et al. (2004) and were transfected using the Transfast Transfection reagent (Promega, Mannheim, Germany) according to the manufacturer's instructions. Western blotting was performed as described by Macchi et al. (2003). Western blots were probed with anti-mouse and anti-rabbit Alexa-800 secondary antibodies, and scanned and analyzed with the Odyssey infrared imaging system (Li-Cor Biosciences, Bad Homburg, Germany). For the antibody competition assay, the Pum2 full-length cDNA was cloned into pGEX-T (Amersham Biosciences, Buckinghamshire, UK) for expression as a glutathione $S$-transferase (GST) fusion in the Escherichia coli strain Rosetta (Novagen, Madison, WI) and purified with Glutathione Sepharose 4 Fast Flow (Amersham Biosciences). Six micrograms of anti-Pum 2 antibody were incubated with 30 $\mu \mathrm{g}$ of purified GST-Pum2 full-length fusion protein for $2 \mathrm{~h}$ at $4^{\circ} \mathrm{C}$ in Detector Block (KPL, Gaithersburg, MD). As a positive control, $6 \mu \mathrm{g}$ of anti-Pum 2 antibody was incubated for $2 \mathrm{~h}$ at $4^{\circ} \mathrm{C}$ in Detector Block. The two solutions were tested on Western blots using rat embryonic brain lysate.

Constructs. Reverse transcription-PCR (RTPCR) was performed on total RNA isolated from embryonic day 17 mouse hippocampus using the RNeasy kit (Qiagen, Hilden, Germany). Mouse Pum 2 cDNA was amplified with PfuTurbo Hotstart DNA polymerase (Stratagene, Heidelberg, Germany) and then cloned in frame with either enhanced yellow fluorescent protein (EYFP) (pEYFP-N1; Clontech, Heidelberg, Germany) or in the same vector in frame with c-myc lacking EYFP. The sequences of the primers used in this study are listed in supplemental Table 1 (available at www. jneurosci.org as supplemental material). All PCR products were sequenced and cloned with NheI/AgeI into the pEYFP-N1 expression vector. For short interfering RNA (siRNA), primers complementary to two distinct regions of rat Pum2 were designed and cloned with BglII and HindIII into the pSUPERIOR vector (OligoEngine, Seattle, WA). See supplemental Table 1 for sequences (available at www.jneurosci.org as supplemental material).

Northern blot. Northern analysis was performed using commercial mouse mRNA blots (Multiple Tissue Northern Blot; Clontech). One kilobase of the cDNA encoding for mouse Pum2 was labeled with $\left[{ }^{32} \mathrm{P}\right]-$ dCTP. The prehybridization and hybridization steps were performed according to the manufacturer's protocol (Clontech).

Pharmacological treatments. Metabolic stress was induced using 0.5 mu Na-arsenite (Sigma, Munich, Germany) for $1 \mathrm{~h}$ (Kedersha et al., 2002). Cells were washed three times with prewarmed HBSS and fixed with $4 \%$ paraformaldehyde (PFA) for $15 \mathrm{~min}$ at room temperature. Immunocytochemistry was performed as described below. Puromycin and cycloheximide were added for $4 \mathrm{~h}$ at final concentrations of 20 and 5 $\mu \mathrm{g} / \mathrm{ml}$, respectively. Nocodazole treatment $(20 \mu \mathrm{M})$ was performed for $3 \mathrm{~h}$ before fixation. For assessing the effects of glutamate on Pum2 expression, neurons were incubated overnight in $1 \mu \mathrm{M} \mathrm{TTX,} 50 \mu \mathrm{M} \mathrm{APV}$, and $100 \mu \mathrm{M}$ CNQX (Sigma) to completely silence synaptic activity. Cells were treated with $10 \mu \mathrm{M}$ glutamate for $2 \mathrm{~min}$ and then incubated in the presence or absence of the inhibitors. Neurons were then washed and incubated for the indicated time in a glutamate-free medium. After these treatments, cells were either fixed and processed for immunocytochemistry or lysed and prepared for Western blotting. 
Immunocytochemistry and fluorescence microscopy. Immunocytochemistry on mature primary hippocampal neurons in culture was performed as described previously (Goetze et al., 2006). Briefly, neurons were washed in HBSS and then fixed in 4\% PFA for $15 \mathrm{~min}$ at room temperature. The following antibodies were used: rabbit polyclonal anti-Pum2 antibodies (dilution, 1:2000; Acris, Hiddenhausen, Germany), mouse monoclonal anti-T-cell intracellular antigen 1 (TIA-1)-related protein (anti-TIAR; dilution, 1:100; Transduction Laboratories, Lexington, $\mathrm{KY}$ ), mouse monoclonal anti-TIA-1 (1:20; Abcam, Cambridge, UK), mouse monoclonal anti-eIF4E (1:100; Santa Cruz Biotechnology, Santa Cruz, CA), rabbit polyclonal anti-poly(A)-binding protein (anti-PABP; 1:100; USBiological, Swampscott, MA), mouse monoclonal anti-tubulin $(1: 10,000)$, mouse monoclonal anti-microtubule-associated protein 2 (anti-MAP2; 1:250), mouse monoclonal anti-Tau (1:250; Chemicon, Temecula, CA), mouse monoclonal antipostsynaptic density 95 (anti-PSD95; 1:2000; all Sigma), mouse monoclonal anti-synaptophysin (1:2000; Boehringer Mannheim, Mannheim, Germany), and mouse monoclonal antiFMRP (1:1000; Chemicon). Cyanine 3- and Alexa 488-coupled goat anti-mouse and antirabbit IgG secondary antibodies (dilution, 1:2000) were used for detection (Dianova, Hamburg, Germany). Phalloidin staining was performed as described by Goetze et al. (2004). The fluorescence microscopy set-up has been described by Macchi et al. (2003). Pictures were acquired using MetaMorph 6.3 (Universal Imaging Corporation, Puchheim, Germany) and assembled with Adobe Photoshop 7.0 (Adobe Systems, San Jose, CA).

Fluorescence in situ hybridization. To detect poly-adenylated mRNA, a 50 nucleotide oligo-dT probe labeled with digoxigenin at the $3^{\prime}$ end by terminal transferase (Roche, Mannheim, Germany) was used. Cells on coverslips were fixed with $4 \%$ PFA in PBSM (PBS with $5 \mathrm{~mm} \mathrm{MgCl}_{2}$ ) at room temperature for $15 \mathrm{~min}$, washed three times with PBSM for $5 \mathrm{~min}$, and then permeabilized in PBSM containing 0.1\% (v/v) Triton X-100 for 3 min. Cells were washed twice with PBSM for $5 \mathrm{~min}$ and equilibrated for $10 \mathrm{~min}$ in $2 \times \mathrm{SSC}, 15 \%$ formamide, and $10 \mathrm{~mm} \mathrm{NaH}_{2} \mathrm{PO}_{4}$ at room temperature. The hybridization was performed for $2 \mathrm{~h}$ at $37^{\circ} \mathrm{C}$ in $20 \mathrm{~mm}$ $\mathrm{NaH}_{2} \mathrm{PO}_{4}, 15 \%$ formamide, $0.2 \% \mathrm{BSA}(2 \mathrm{mg} / \mathrm{ml}), 10 \%$ dextran sulfate, $2 \times$ SSC, $0.5 \mathrm{mg} / \mathrm{ml}$ E. coli tRNA, $0.5 \mathrm{mg} / \mathrm{ml}$ denatured herring salmon sperm DNA, and $250 \mathrm{ng} / \mathrm{ml}$ of probe. After hybridization, cells were washed in $15 \%$ formamide, $2 \times \mathrm{SSC}$ at $37^{\circ} \mathrm{C}$ for $20 \mathrm{~min}$, and three times for $10 \mathrm{~min}$ in $1 \times$ SSC at room temperature. Cells were then blocked for 30 min in $1 \times$ blocking solution (Roche) and incubated with rhodaminelabeled anti-Dig Fab fragments (Roche) and anti-Pum2 antibodies.

Sucrose gradient centrifugation. Adult rat brain was homogenized in ice-cold extraction buffer (10 mm Tris, pH 7.4, $100 \mathrm{~mm} \mathrm{NaCl}, 20 \mathrm{~mm}$ $\mathrm{MgCl}_{2}, 200 \mu \mathrm{g} / \mathrm{ml}$ heparin, standard protease inhibitor mixture) in the presence of either cycloheximide $(100 \mu \mathrm{g} / \mathrm{ml})$ or puromycin $(100 \mu \mathrm{g} /$ $\mathrm{ml}$ ). The lysates were then cleared by spinning at 20,817 relative centrifugal force ( $\mathrm{rcf}$ ) for $10 \mathrm{~min}$ at $4^{\circ} \mathrm{C}$. Nine hundred microliters of supernatant were loaded on top of a $10 \mathrm{ml} 15-50 \%$ linear sucrose gradient made in extraction buffer. The samples were centrifuged in a swinging bucket rotor (SW41Ti; Beckman Coulter, Krefeld, Germany) at 151,263 rcf at $4^{\circ} \mathrm{C}$ for $2.5 \mathrm{~h}$. Twelve fractions were collected and run onto a $10 \%$ SDS-PAGE.

Time-lapse video microscopy. For imaging, HeLa cells and primary hip- pocampal neurons were transferred into HBSS (in mM: 20 HEPES, 1 $\mathrm{Na}_{2} \mathrm{HPO}_{4}, 135 \mathrm{NaCl}_{2}, 4 \mathrm{KCl}, 2 \mathrm{CaCl}_{2}, 1 \mathrm{MgCl}_{2}$, and 10 glucose in doubledistilled $\mathrm{H}_{2} \mathrm{O}$ ) and placed into an imaging chamber mounted onto an Axiovert 100TV inverted microscope (Zeiss, Oberkochen, Germany). During the experiment, the cells were maintained at constant temperature $\left(36.5^{\circ} \mathrm{C}\right)$ in a humidity chamber. Images were acquired at a rate of one image per $20 \mathrm{~s}$ for neurons and one image per $30 \mathrm{~s}$ for HeLa cells using a liquid nitrogen-cooled Spec-10 LN/CCD-400B digital camera (quantum yield, 94\%; Roper Scientific, Tucson, AZ), a 40× PlanNeofluor (numerical aperture, 1.30) oil immersion objective (Zeiss), and the MetaMorph 6.1 imaging software package (Universal Imaging Corporation). Time-lapse videos were generated using MetaMorph 6.1 and the QuickTime PlayerPro 7.0.3 software packages (Apple Computer, $\mathrm{Cu}$ pertino, CA). Images were not modified other than adjustments of levels, brightness, contrast, and magnification.

Data analysis. All quantifications were tested for significance with $t$ tests and were considered significant if $p<0.05$ and expressed as SEM.

\section{Results}

Subcellular localization of Pum2 in cultured hippocampal neurons

Expression of mammalian Pum2 was tested by Northern blot of different mouse tissues (Fig. 1A). A single transcript was expressed at high levels in both heart and brain. Lower levels of Pum2 were detected in liver and kidney. Two transcripts at a 
A
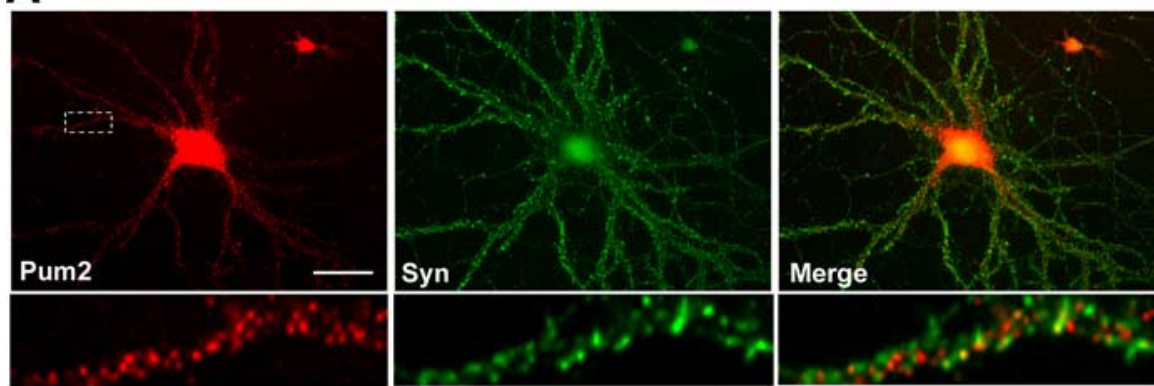

B
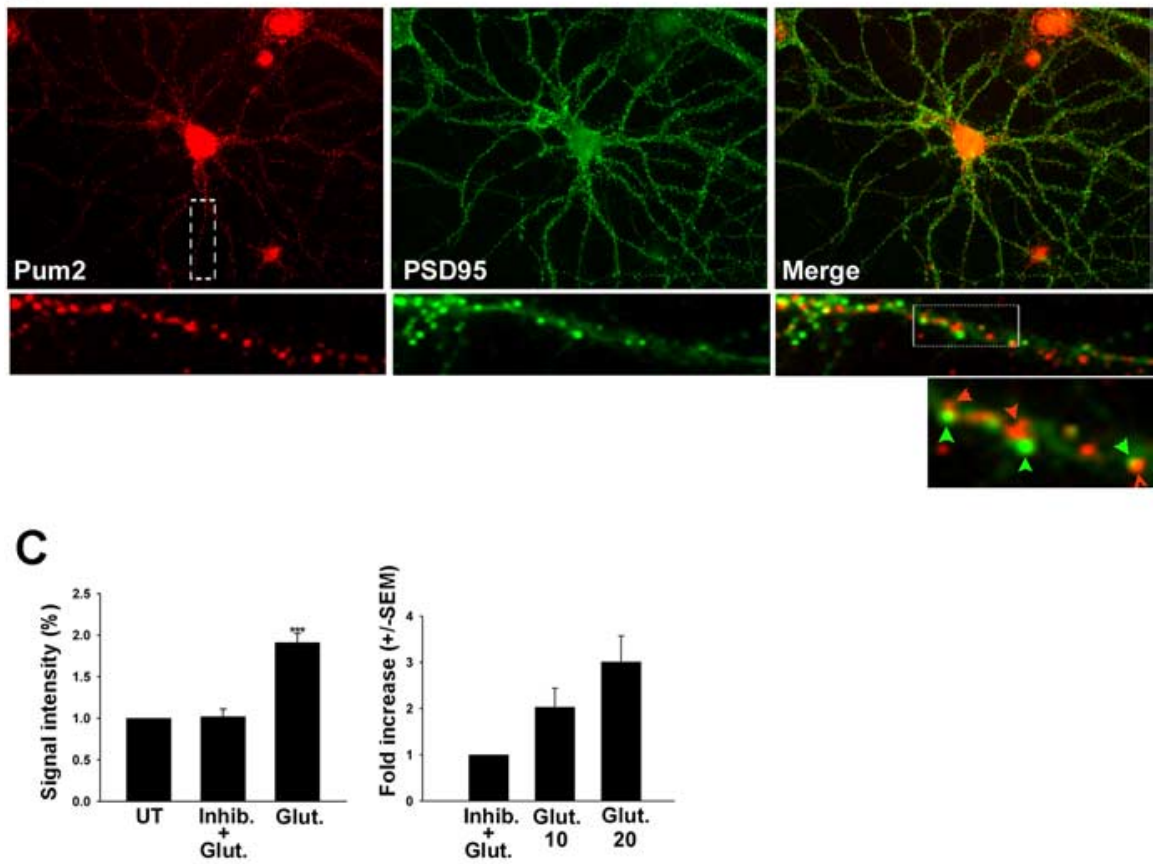

Pum2

Tubulin

Figure 3. Pum 2 is excluded from dendritic spines but is upregulated after synaptic activation. $A$, Immunostaining for Pum 2 (red) and synaptophysin (Syn; green) performed on 15 DIV hippocampal neurons. The dendritic enlargements show that Pum 2 is not colocalizing with presynaptic terminals. $\boldsymbol{B}$, Pum 2 is found in the dendritic shaft within close proximity of the base of dendritic spines. Immunostaining for Pum2 (red) and the postsynaptic marker PSD95 (green) demonstrates close apposition of PSD95 puncta and Pum 2 particles. Scale bar, $10 \mu \mathrm{m}$. C, Synaptic activation leads to an increase in Pum 2 protein levels. Neurons were treated overnight with a synaptic inhibitor mixture (see Materials and Methods) and then with $10 \mu \mathrm{m}$ glutamate for 2 min before washing and incubation in a glutamate free medium. The left graph depicts the twofold increase in Pum 2 immunofluorescence intensity as measured in the cell body (Glut.). Control experiments consisted of cells receiving no glutamate (UT) and cells receiving glutamate in the presence of the synaptic inhibitors (Inhib. + Glut.). Data was normalized to the untreated group. The right graph demonstrates the increase in Pum2 protein levels as assessed by Western blotting $(n=2) .10$ min after exposure to glutamate (Glut. 10), Pum2 protein levels had increased approximately twofold and had increased almost threefold after 20 min (Glut. 20). Using the Li-Cor Odyssey Infrared Imaging System, blots were scanned and the Pum2 signal was expressed as a ratio to tubulin protein levels before normalization to the control treatment group (Inhib. + Glut.). Error bars represent SEM.

lower molecular weight were found in testis. In contrast, the expression of Pum2 in spleen, lung, and muscle was negligible. These data confirm previous findings of mammalian Pum2 expression (White et al., 2001; Spassov and Jurecic, 2002). As a result of the importance of Pum in Drosophila long-term memory (Dubnau et al., 2003), we focused on cultured hippocampal neurons. Semiquantitative RT-PCR analysis showed that the Pum2 transcript was detected during the differentiation of cultured hippocampal neurons (data not shown). Expression persisted in fully polarized neurons. We next set out to characterize Pum2 protein distribution in cultured hippocampal neurons using a

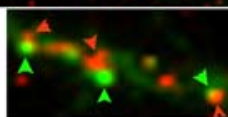

polyclonal anti-Pum2 antibody. We found that Pum2 is highly expressed in neurons, whereas expression in glia was negligible (Fig. $1 B$ ). Immunostaining of mature neurons revealed that Pum2 protein is present in the cell body and processes (Fig. 1C,D). Moreover, the staining pattern was not homogeneous, but distinct particles were clearly visible.

To determine whether Pum2 was found predominantly in dendrites or axons, neurons were costained with either MAP2 or Tau, two markers specific for dendrites and axons, respectively. Few particles were observed in axons (Fig. $1 D)$, with the majority of Pum2 staining found in the MAP2-positive processes (Fig. 1C). These data indicate that Pum2 preferentially localizes into the somatodendritic compartment of polarized neurons. Immunostaining performed during the different stages of development of cultured neurons confirmed the expression of Pum2 in dendrites during all stages of neuronal polarization (data not shown).

The presence of Pum2 in dendrites prompted us to investigate whether this localization was dependent on microtubules. Double immunostaining for tubulin and Pum2 showed significant colocalization, suggesting that Pum2 associates with polarized microtubular tracks (Fig. $2 A)$. Consistent with this result, the treatment of neurons with $20 \mu \mathrm{M}$ nocodazole strongly reduced the Pum2 signal in dendrites (Fig. $2 B$ ). In contrast, Pum2 particles did not colocalize with filamentous actin (F-actin) in dendrites, as shown with phalloidin staining of neurons (Fig. 2C). We further assessed the subcellular localization of Pum2 in dendrites by double immunostaining for Pum2 and for either presynaptic or postsynaptic markers (Fig. 3). Synaptophysin 1 staining (Fig. 3A) did not reveal an obvious colocalization with presynaptic terminals. However, costaining with PSD95 (Fig. 3B) revealed that discrete Pum2 particles were distributed along the dendritic shaft beneath PSD95positive puncta. The distribution of such Pum2 particles was essentially homogenous. In some instances, we observed Pum2 particles in close proximity to dendritic spines (Fig. 3B, enlargement), an observation consistent with that of another dendritically localized RNA-binding protein, Staufen2 (Goetze et al., 2006). After quantification of three independent experiments, $29.1 \pm 1.5 \%$ ( $n=1094)$ of the total Pum2 particles were adjacent to PSD95 puncta. Similarly, $35.0 \pm 1.7 \%(n=927)$ of the total PSD95 puncta were adjacent to a Pum2 particle.

\section{Synaptic activity increases Pum2 protein levels in neurons}

Synaptic activity is known to increase the synthesis of mRNA in neurons (Wu et al., 1998). Because Pum2 is known to act as a 
translational inhibitor in Drosophila ( $\mathrm{Pa}-$ risi and Lin, 2000) and translational inhibitors are likely necessary for preventing the improper translation of mRNA during RNP transport (Dahm and Kiebler, 2005), we hypothesized that glutamate stimulation of cultured neurons would result in an increase in Pum 2 protein. Neurons were incubated overnight in a mixture of synaptic inhibitors $(1 \mu \mathrm{M}$ TTX, $50 \mu \mathrm{M}$ APV, and $100 \mu \mathrm{M}$ CNQX). After this treatment, neurons were subjected to stimulation with 10 $\mu \mathrm{M}$ glutamate in the presence or absence of the inhibitor mixture. This stimulation with glutamate led to a significant increase in Pum 2 protein in the cell body (Fig. 3C, left graph). The average fluorescence intensity, when normalized to the control condition consisting of antagonist only, was significantly increased by $91.0 \pm$ $11.0 \%(p<0.01)$. This finding could be attributed to either new Pum2 protein production or an increase in somatic Pum 2 caused by additional protein being recruited from the distal dendrites. To clarify which mechanism was responsible, we repeated the experiments and analyzed Pum2 protein levels via Western blotting (Fig. 3C, right graph). When subjected to fluorescence intensity analysis and normalized to tubulin protein levels, it was evident that the increase in Pum2 fluorescence in the soma arises because of an overall increase in Pum2 protein levels. When treated for 2 min with $10 \mu \mathrm{M}$ glutamate and then washed in HBSS for $10 \mathrm{~min}$, Pum2 protein increased approximately twofold. After $20 \mathrm{~min}$, Pum 2 protein levels had increased threefold over control conditions.

Pum2 is found in ribonucleoparticles and is recruited into dendritic stress granules

To better characterize the molecular properties of Pum2, we fractionated brain cytoplasmic extracts on a $15-50 \%$ sucrose density gradient. Fractions were recovered and analyzed by Western blotting with antiPum2, anti-Staufen1, and anti-L7a antibodies. In the presence of either cycloheximide or puromycin (data not shown), a significant amount of Pum2 was found in fractions of lower density devoid of ribosomes. In contrast to Stau1, Pum2 did not cofractionate with the major peak of ribosomes (Fig. 4A). These data suggest that Pum2 does not associate with polyribosomes or ribosomal subunits and thus behaves like Smaug, another RNA-binding protein that acts as a translational inhibitor (Baez and Boccaccio, 2005).

To determine whether the small Pum2 puncta observed in dendrites contain mRNA and can be considered RNPs, fluores-

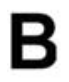

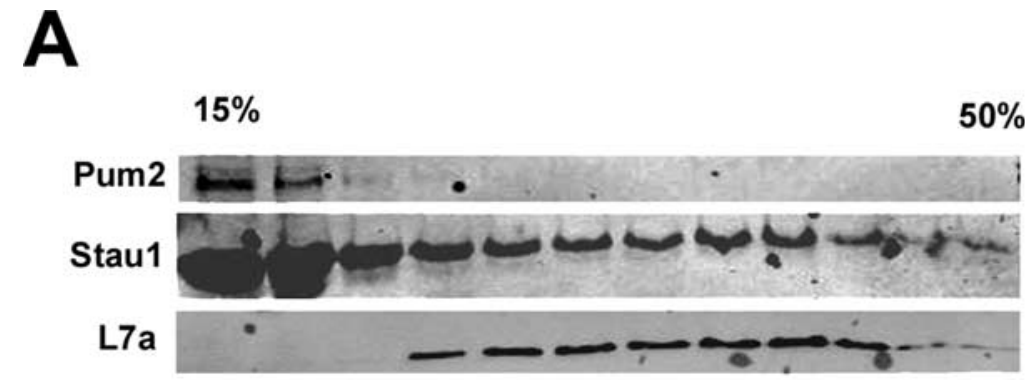
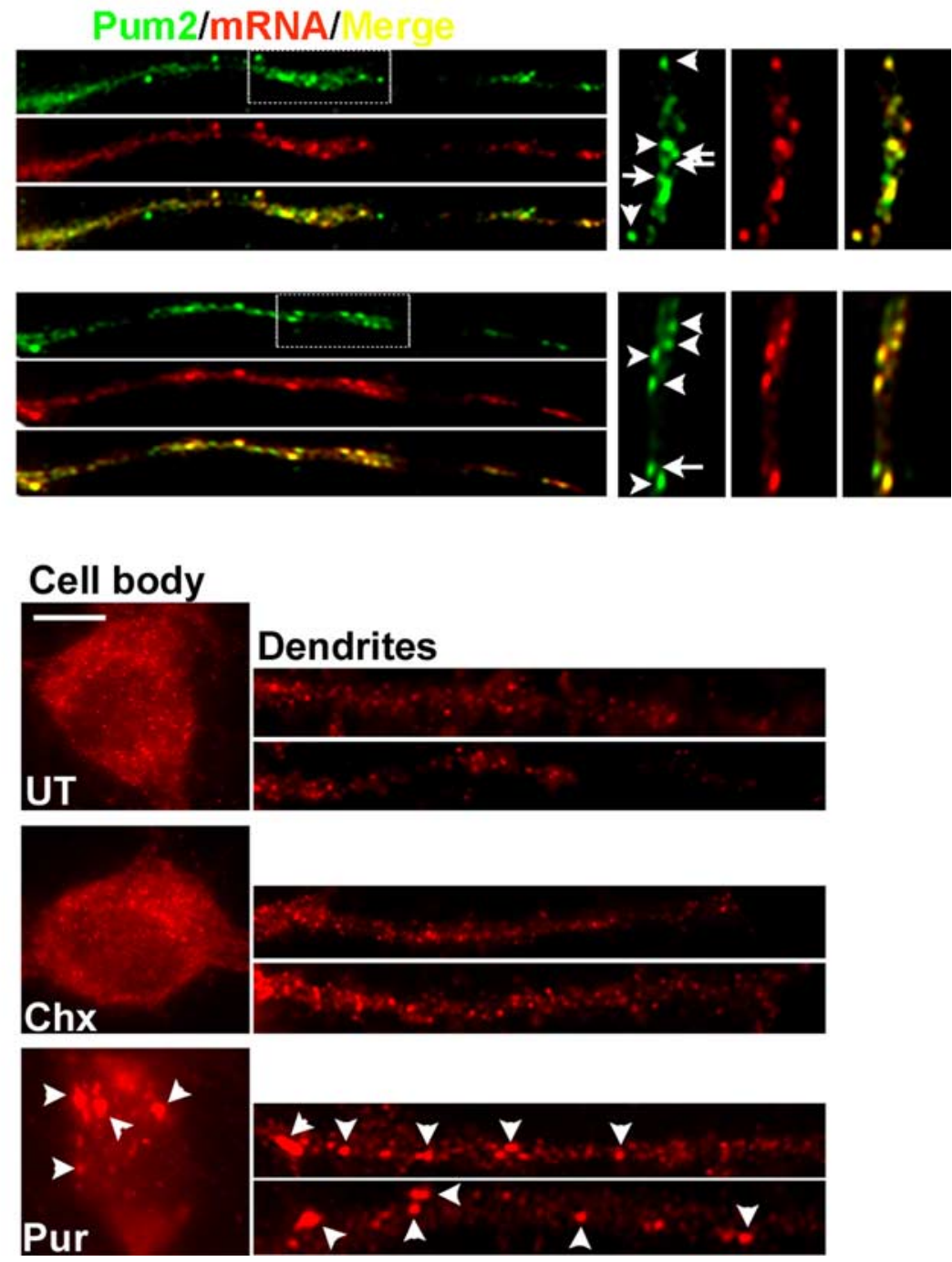

Figure 4. Pum2 is a component of RNPs and forms SGs after disruption of translation. $A$, Fractionation of adult rat brain extract by $15-50 \%$ sedimentation sucrose gradient centrifugation. A Western blot was performed on fractions to detect Pum2, Staufen1, and the large ribosomal subunit L7a. B, Dendritic Pum2 puncta contain mRNA. Immunostaining for Pum2 (green) was combined with FISH using an oligo-dT probe to detect mRNA. Pum2-containing puncta showed strong colocalization with mRNA (red). Some Pum2 puncta did not contain mRNA (arrows), whereas all mRNA contained Pum2 (arrowheads). C, Puromycin treatment alters the cellular distribution of Pum2 particles. Hippocampal neurons were treated with $20 \mu \mathrm{g} / \mathrm{ml}$ puromycin for $4 \mathrm{~h}$ and immunostained for Pum2 (Pur). After drug treatment, Pum2 formed large aggregates in the cell body. Similar rearrangement occurs in dendrites (arrowheads). In contrast, no changes in Pum2 subcellular localization was observed in neurons treated with cycloheximide (Chx). UT, Untreated. Scale bar, $5 \mu \mathrm{m}$.

cence in situ hybridization (FISH) using oligo-dT probes was performed in combination with Pum2 immunocytochemistry (Fig. $4 B$ ). In distal dendrites, all mRNA puncta contained Pum2; however, not all Pum2 puncta colocalized with mRNA. These data indicate the majority of Pum2 particles represent RNPs, a 


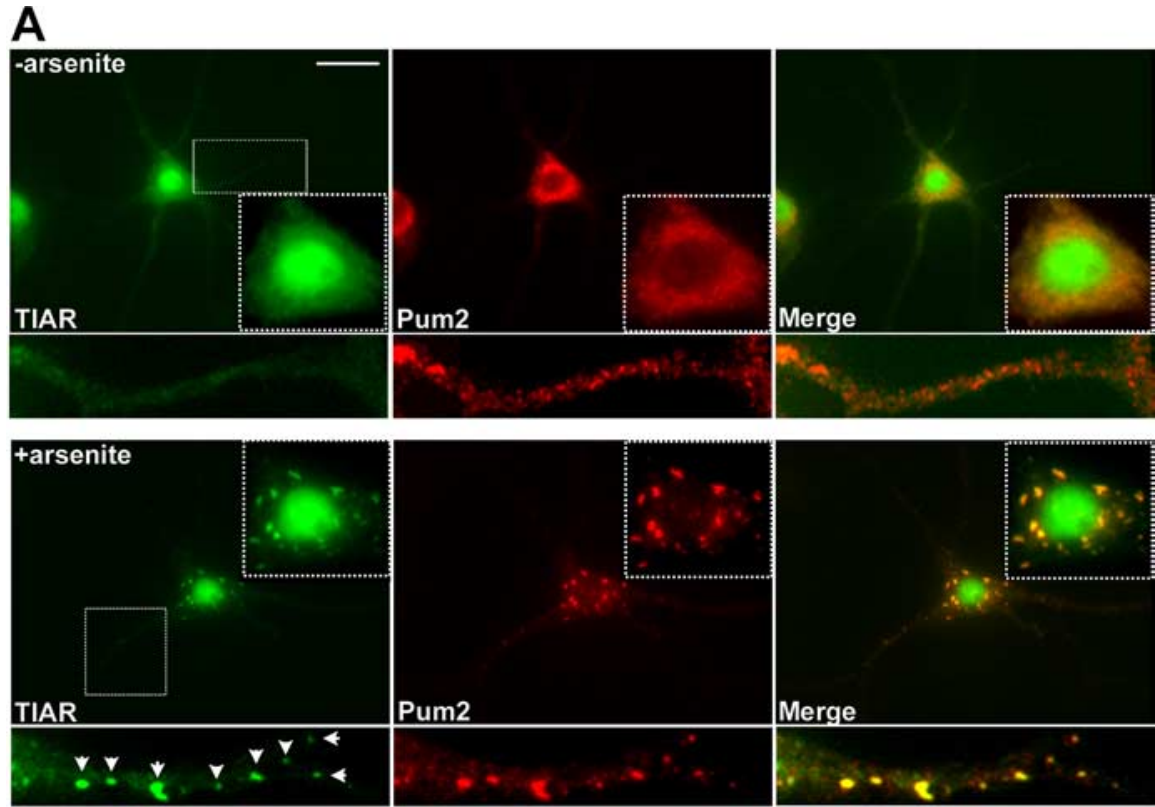

B
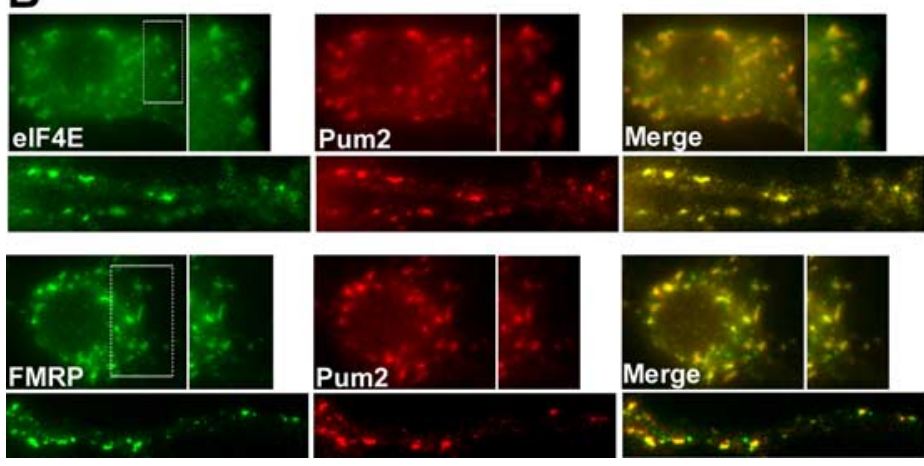

Figure 5. Metabolic stress recruits Pum2 into stress granules. $\boldsymbol{A}$, Fifteen DIV hippocampal neurons were stained for TIAR (green) and Pum2 (red) before (top) or after (bottom) treatment with $500 \mu \mathrm{m}$ arsenite for $1 \mathrm{~h}$. In the absence of stress, TIAR is primarily nuclear with low levels of diffuse staining in the soma and dendrites. In the presence of stress, Pum 2 colocalizes with TIAR in both the cell body (shown at a lower exposure in the top or bottom corners) and distal dendrites (see enlargements and arrowheads). $\boldsymbol{B}$, elF4E and FMRP also colocalize with Pum 2 after arsenite treatment. This colocalization occurs in both the cell body (top) and in dendrites (bottom). Scale bar, $10 \mu \mathrm{m}$.

finding similar to other RNA binding proteins such as Staufen (Monshausen et al., 2001; Tang et al., 2001; Mallardo et al., 2003) and Barentsz (Btz) (Macchi et al., 2003).

The PuF family of proteins act as inhibitors of translation in many organisms (Parisi and Lin, 2000; Baines, 2005; de Moor et al., 2005). Because Pum2-associated polyadenylated mRNA might be silenced for translation or associated with translating ribosomes, we therefore investigated the effects of protein synthesis inhibitors that affect polysome stability on Pum2 distribution. We incubated hippocampal neurons in the presence of puromycin followed by immunostaining for Pum2 (Fig. 4C). Puromycin treatment caused a significant rearrangement of the endogenous Pum 2 particles. In contrast to untreated neurons that showed small Pum2 puncta distributed homogeneously throughout the somatic cytoplasm, treatment of neurons with puromycin led to the formation of larger granules. Similar changes in Pum 2 distribution were also observed in dendrites, in which Pum 2 particles were clustered into larger aggregates along the dendritic shaft (Fig. 4C, dendrite). In contrast, treatment with cycloheximide $(10 \mu \mathrm{g} / \mathrm{ml})$ did not alter the Pum2 staining pat- tern (Fig. 4C). The large granules that formed in the presence of puromycin were reminiscent of SGs. It has been reported that various cellular stresses, including puromycin treatment, induce the accumulation of a number of RNA-binding proteins such as Staufen (Thomas et al., 2005), FMRP (Mazroui et al., 2002), and elements of the translational machinery including PABP and eIF4E into SGs (Kedersha et al., 2005).

To determine whether metabolic stress indeed recruited Pum2 into SGs, we treated hippocampal neurons with $500 \mu \mathrm{M}$ arsenite for $60 \mathrm{~min}$. We first tested the staining pattern of TIAR, an RNA-binding protein that is a well established marker for SGs (Kedersha et al., 1999), before and after treatment with arsenite (Fig. 5A). In the absence of arsenite, TIAR is primarily found in the nucleus with weak homogeneous staining detectable in both the cell body and dendrites. After arsenite treatment, discrete granules were observed in both compartments, suggesting that TIAR, primarily a nuclear protein, was recruited to distal dendrites (Fig. 5A, arrowheads). As shown in Figure $5 A$, these large granules also contain Pum2. Interestingly, Pum2/TIAR-positive granules were detected in dendrites (Fig. 5A, enlargements). To illustrate the degree of colocalization along the length of a representative dendrite, line-scan profiles of the fluorescence intensity of both fluorophores (the red and green channels) are shown in supplemental Figure 1 (available at www. jneurosci.org as supplemental material). To further clarify that these aggregates containing Pum2 were indeed SGs, we tested for other known components of these structures. After induction of SG formation, we performed immunostaining for Pum2 together with eIF4E or FMRP, two proteins previously shown to be present in SGs (Mazroui et al., 2002; Kimball et al., 2003; Kedersha et al., 2005; Kim et al., 2006). We found that, like TIAR, both proteins were present in Pum2-containing SGs in both the cell body and dendrites (Fig. $5 B$ ).

To determine whether Pum2-positive SGs also contained mRNA, we performed immunostaining combined with FISH using labeled oligo-dT probe in stressed and unstressed neurons (Fig. 6A). Pum2-containing SGs showed a high degree of colocalization with mRNA-containing granules (see also supplemental Fig. S1, available at www.jneurosci.org as supplemental material). Together, these data demonstrate that Pum2 represents a novel component of SGs in both the cell body and dendrites. This is the first evidence that dendritic SGs exist, supporting the idea that a stress-related translational control mechanism is present in dendrites in which localized mRNA undergoes local protein synthesis in hippocampal neurons (Steward and Schuman, 2001).

We then tested whether Pum2-containing SGs were static after formation or dynamic structures (Kedersha et al., 2000). Stress was induced with arsenite treatment in the presence of 
cycloheximide or puromycin (Fig. 6B,C). In contrast to puromycin, which causes premature chain termination releasing ribosomes from mRNA, cycloheximide stabilizes polysomes by inhibiting elongation. Treatment with arsenite in the presence of puromycin did not interfere with the recruitment of Pum2 into SGs (Fig. 6C). Similar results were obtained after staining with Pum2 and eIF4E (Fig. $6 D)$. In contrast, cycloheximide prevented the formation of Pum2-positive SGs (Fig. $6 B)$. Because cycloheximide, like emetine (Kedersha et al., 2000), traps mRNA in polysomes, it prevents the de novo formation of SGs in the presence of the stress stimuli. These data therefore suggest that, during stress, Pum2-containing SGs are in dynamic equilibrium with polysomes.

\section{Pum2 is excluded from P-bodies}

SGs are functionally distinct from P-bodies, which are cytoplasmic sites of mRNA storage and degradation (Sheth and Parker, 2003; Cougot et al., 2004, Liu et al., 2005). Neurons were transfected with a construct expressing enhanced green fluorescent protein (EGFP)-tagged Dcpla, a known component of P-bodies (Lykke-Andersen, 2002), to determine whether Pum2 also associates with these structures. Few discrete Dcpla-EGFP granules were found in dendrites of untreated neurons (Fig. 7A, - arsenite). These granules, in contrast to TIARcontaining SGs, did not colocalize with Pum2 either in the presence or absence of arsenite (Fig. 7, enlargement; see also supplemental Fig. S1, available at www. jneurosci.org as supplemental material). Interestingly, during stress treatment, we observed a twofold increase in the number of Dcp la-GFP granules in distal regions of the dendrites. In the absence of stress, there were $0.38 \pm 0.032$ Dcpla-GFP puncta per $10 \mu \mathrm{m}$ of dendrite length. In the presence of arsenite, the number of puncta increased to $0.78 \pm 0.064 \mathrm{Dcpla}-\mathrm{GFP}$ puncta per $10 \mu \mathrm{m}$ of dendrite length $(p<0.001)$. However, these granules still did not colocalize with Pum2-containing SGs (Fig. 7A).

To further illustrate that Pum2 was found in SGs but was excluded from P-bodies after arsenite treatment, we expressed GFP-tagged Pum2 in hippocampal neurons followed by immunostaining for both TIAR and Lsm1, a protein found in P-bodies (Ingelfinger et al., 2002). Stress induction led to the formation of large TIAR-positive aggregates of Pum2-EYFP along dendrites (Fig. 7C). In contrast, Lsm 1 granules were adjacent to, but not colocalizing with, Pum2-EGFP (Fig. 7C). These data show that Pum2 is specifically recruited to SGs but not P-bodies in dendrites of hippocampal neurons.

\section{Pum2 facilitates SG formation}

To analyze the role of Pum2 in SG formation, full-length Pum2 $\left(\right.$ Pum2 $2_{\mathrm{FL}}$ ) (for a scheme, see Fig. $8 A$ ) tagged with EYFP was ex- pressed under the control of the cytomegalovirus promoter (Fig. $8 B, C)$ in HeLa cells. It was found that even in the absence of stress stimuli, when fixed $18-24 \mathrm{~h}$ after transfection and stained for TIAR, $74.5 \pm 1.2 \%$ of transfected cells form Pum2-containing SGs that are also positive for TIAR (Fig. 8C, FL). Eighteen to $24 \mathrm{~h}$ after transfection and after induction of metabolic stress with arsenite, Pum2-EYFP was recruited into SGs in $>95 \%$ of transfected cells (data not shown). The addition of cycloheximide dispersed SGs induced by Pum2 overexpression (data not shown), again suggesting that these structures are dynamic. Similar observations were made in neurons in which granules formed by overexpression of Pum $2_{\mathrm{FL}}$ also led to the recruitment of other RNAbinding proteins such as Staufen 1 and Btz (supplemental Fig. S2 B, available at www.jneurosci.org as supplemental material). These proteins are involved in RNA transport and nonsensemediated decay (Palacios et al., 2004; Kim et al., 2005). This further indicates that the granules induced after overexpression are comparable with SGs formed during the stress response. 
However, in contrast to this observation, staining for endogenous Pum2 after transfection with cytoplasmic polyadenylation element-binding protein (CPEB)-GFP and Maskin-cyan fluorescent protein (CFP) and treatment with arsenite demonstrated that these two RNP proteins were not recruited to the same granules as Pum2 (supplemental Fig. S3A, available at www.jneurosci.org as supplemental material). Together, this is the first indication that Btz is a component of SGs and also demonstrates that there may be multiple subtypes of SGs in neurons.

To determine which region of the Pum2 protein is responsible for the induction of SGs, we generated different fluorescence-tagged fusion constructs: the $\mathrm{N}$-terminal region (Pum2 $2_{1-651}$; amino acids 1-651) and the C-terminal portion (Pum2 $\left.{ }_{650-S t o p}\right)$ that contains the RNAbinding Pumilio homology domain (PHD) (Fig. 8A). Because the C-terminal $\mathrm{PHD}$ is responsible for RNA binding, we expected to observe SG formation during its overexpression, and the transfection of Pum $2_{650-S t o p}$ did induced SG formation in $73 \pm 1.2 \%$ of transfected cells (Fig. 8 Bii). A significant nuclear accumulation was also observed. After induction of stress, Pum $2_{650-\text { Stop }}$ was found in discrete granules positive for TIAR in almost $100 \%$ of transfected cells (data not shown). The overexpression of Pum $2_{1-651}$ also induced SG formation (Fig. 8 Biii). The number and the morphology of Pum P $_{1-651}$ granules were, however, different when compared with endogenous SGs or SGs induced by overexpression of Pum $2_{\mathrm{FL}}$ and Pum $2_{650-\text { Stop. }}$ They were fewer in number and consistently smaller in size. The majority of the fluorescence signal displays a homogeneous cytoplasmic distribution. Similar results were observed when Pum2 $2_{\text {FL }}$, Pum $2_{1-651}$, and the Pum $2_{650-S t o p}$ constructs were overexpressed in neurons, suggesting that the ability of Pum2 to induce SG formation is not specific to a certain cell type. A quantification of three independent experiments in HeLa cells is shown in Figure $8 C$.

We then set out to determine the time course of SG formation after initiation of the stress response. HeLa cells and neurons were imaged $6-8 \mathrm{~h}$ after transfection of Pum $2_{\mathrm{FL}}$, before SGs formed, and $500 \mu \mathrm{M}$ arsenite was added to neurons displaying transfected and untransfected cells (Fig. 8D). Images were acquired every $30 \mathrm{~s}$ for $57 \mathrm{~min}$. Discrete aggregates of the fluorescently tagged Pum 2 protein were evident in the cell soma and dendrites at $16 \mathrm{~min}$. This time course of neuronal SG formation is comparable with that observed in cultured HeLa cells (supplemental Fig. S1C, available at www.jneurosci.org as supplemental material) and to that previously reported in COS cells transfected with GFP-tagged TIA-1 (Kedersha et al., 2000).

The ability of the N-terminal portion of Pum2 to induce SG formation and to recruit TIAR after overexpression prompted us to further investigate whether a specific domain was responsible for the observed effect. The Pum2 protein contains a poly $\mathrm{Q}$ (glutamine)-rich region (QRR) located upstream of the PHD (supplemental Fig. S2 A, available at www.jneurosci.org as supplemental material). Because this domain was present in the Pum $_{1-651}$ construct, we tested whether a smaller part of the $\mathrm{N}$-terminal half containing the QRR domain was still sufficient for the induction of SGs. Two different constructs of the $\mathrm{N}$ terminus were therefore created, the first containing amino acids 1-226 (Pum2 ${ }_{1-226}$ ) in which no relevant domains or amino acid sequences have been identified, and the second (Pum2 $225-651$ ) containing the QRR region. The mere overexpression of fulllength Pum2 leads to SG formation in HeLa cells, whereas Pum $2_{1-226}$ displayed a homogenous cellular distribution (Fig. $9 A i)$. This region was not recruited into $S G s$ even during arseniteinduced metabolic stress (data not shown). Pum2 $2_{1-651}$ induces the formation of two distinct populations of aggregates: large cytoplasmic granules that recruited TIAR and small foci that were 
visible within the cytoplasm and the nucleus that did not recruit TIAR (Fig. 9Aii and inset). In contrast, expression of Pum $2_{225-651}$ only induced small foci (Fig. 9Aiii). Because these small aggregates were reminiscent of P-bodies because of their size and shape, we immunostained transfected HeLa cells for both TIAR and Lsm1 (Fig. 9B,C). As shown in neurons, the overexpression of $\mathrm{Pum} 2_{\mathrm{FL}}$ induced the formation of TIAR-positive SGs. Although Pum 2 and TIAR colocalized, Lsm 1 was consistently excluded. Interestingly, the overexpression of Pum2 $225-651$ induced the formation of small aggregates that caused an accumulation of TIAR in the absence of metabolic stress. However, the Pum2 225-651 aggregates did not overlap with the TIAR granules but were adjacent to them. They also remained excluded from P-bodies (Fig. 9C).

We then determined whether the overexpression of Pum $2_{\mathrm{FL}}$ and Pum $2_{225-651}$ led to the recruitment of other components of SGs by staining HeLa with eIF4E, PABP, and TIA-1 (Fig. 10). As expected, Pum $2_{\mathrm{FL}}$ overexpression formed aggregates containing all SG markers. Similarly, the overexpression of Pum 2 225-651 caused a rearrangement of TIA-1, eIF4E, and PABP in a similar manner to that of TIAR. PABP, another known component of SGs (Kedersha et al., 2005), was also recruited to these structures in neurons treated with arsenite (supplemental Fig. $\mathrm{S} 3 B$, available at www.jneurosci.org as supplemental material).

\section{Downregulation of Pum2 interferes with SG assembly}

Because Pum2 overexpression alone was capable of inducing SG formation, we next hypothesized that the loss of Pum2 may interfere with this process in the presence of stress stimuli. We therefore knocked down Pum2 expression using RNA interference (RNAi) in polarized hippocampal neurons. Nineteen-mer oligonucleotides directed against two regions of the Pum 2 cDNA were cloned into the pSUPERIOR vector (Brummelkamp et al., 2002). Constructs expressing siRNA complementary to two regions of rat Pum2 (siPum2-1 and si-Pum2-2) were tested for their ability to reduce the level of the heterologously expressed Pum2 tagged with c-myc in COS cells (supplemental Fig. S3C, available at www. jneurosci.org as supplemental material). The expression of the si-Pum2-1 construct led to a significant reduction $(\sim 60 \%)$ of Pum2-myc expression. Moreover, coexpression of a mismatched sequence of siPum2 (mis-Pum2-1) did not alter the level of Pum2-myc tagged protein (supplemental Fig. S3C, available at www.jneurosci.org as supplemental material). To verify downregulation of endogenous Pum2 in vivo, $15 \mathrm{~d}$ in vitro (DIV) neurons were transfected with si-Pum2-1 and misPum2-1 pSUPERIOR vectors and then immunostained for Pum2 3 d after transfection. si-Pum2-1 and si-Pum2-2 sub-
B
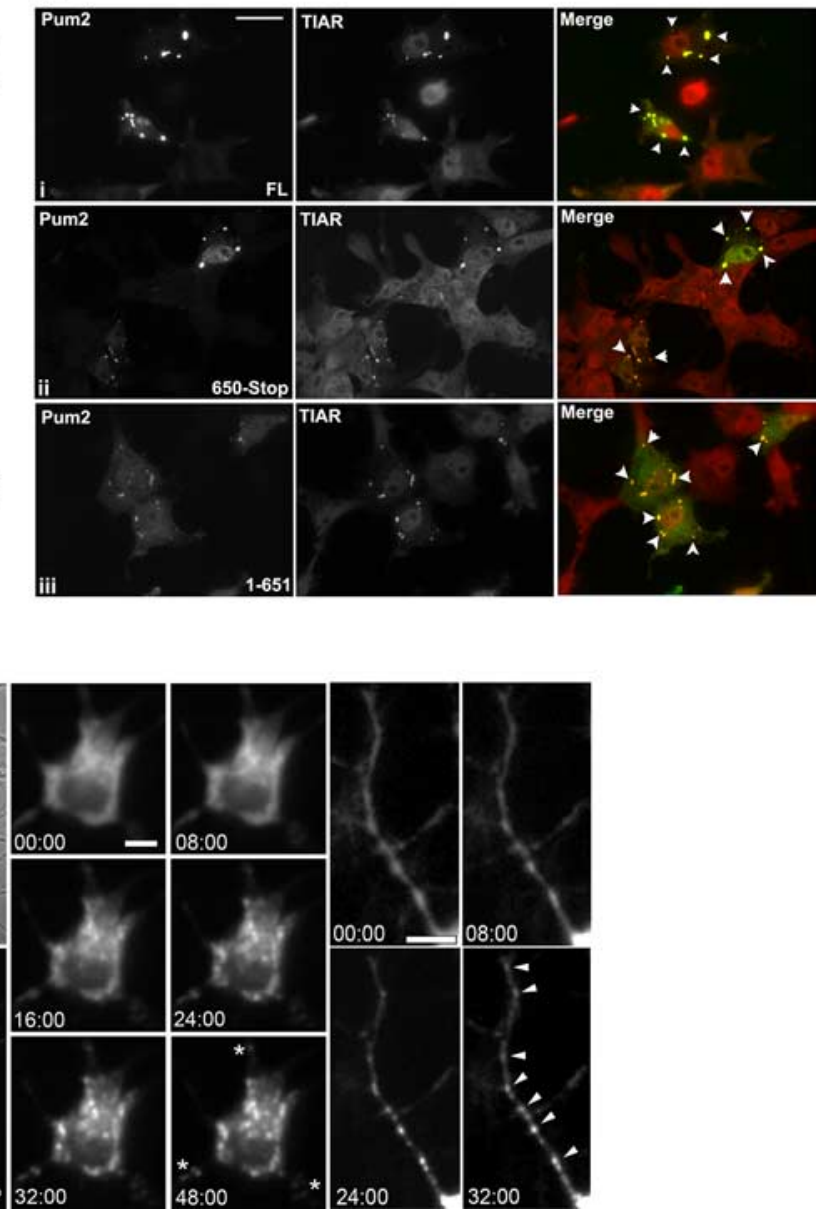

Figure 8. Overexpression of Pum 2 is sufficient for SG induction. $\boldsymbol{A}$, Scheme of the Pum 2 constructs transfected in HeLa cells. $\boldsymbol{B}$, 作 (6) constructs significantly induce SG formation after overexpression. Error bars represent SEM. ${ }^{*} p<0.05 ;{ }^{* *} p<0.01 ;{ }^{* * *} p$ point 0 ) and imaged over $57 \mathrm{~min}$. SG formation is first detected in the cell body and dendrites (arrowheads) $\sim 16$ min after the addition of arsenite. The phase contrast image in the top left corner shows the neurons at the beginning of the time-lapse video before the addition of arsenite. The asterisks indicate SGs in proximal dendrites. Scale bars: bottom left, $10 \mu \mathrm{m}$; enlargements, $5 \mu \mathrm{m}$. Videos are available on request.

stantially reduced Pum2 expression in neurons. In contrast, mis-Pum2-1 and mis-Pum2-2 did not alter expression levels (supplemental Fig. S3D, available at www.jneurosci.org as supplemental material and data not shown).

Three days after transfection, hippocampal neurons expressing either si-Pum2-1 or mis-Pum2-1 were treated with $500 \mu \mathrm{M}$ arsenite for $1 \mathrm{~h}$ and then analyzed for SG formation via TIAR immunostaining (Fig. 11). Both si-Pum2 plasmids, compared with their respective mismatch controls, caused a significant reduction in the number of neurons forming TIAR-positive SGs. After quantification of three independent experiments, both siPum2 plasmids significantly reduced the number of cells forming SGs from $\sim 80$ to $\sim 55 \%$ ( $p<0.05)$. The remaining SGs observed in RNAi-treated neurons were often of altered morphology. They were smaller in size and primarily restricted to the soma. Also noticed in neurons expressing the si-Pum2 plasmids was a mild reduction in the size of the soma (data not shown). To demon- 


\begin{tabular}{|l|l|l|l|l|}
\hline $1-651$ & QRR \\
$1-226 \square$ & GFP \\
$225-651$ & GFP \\
\hline
\end{tabular}
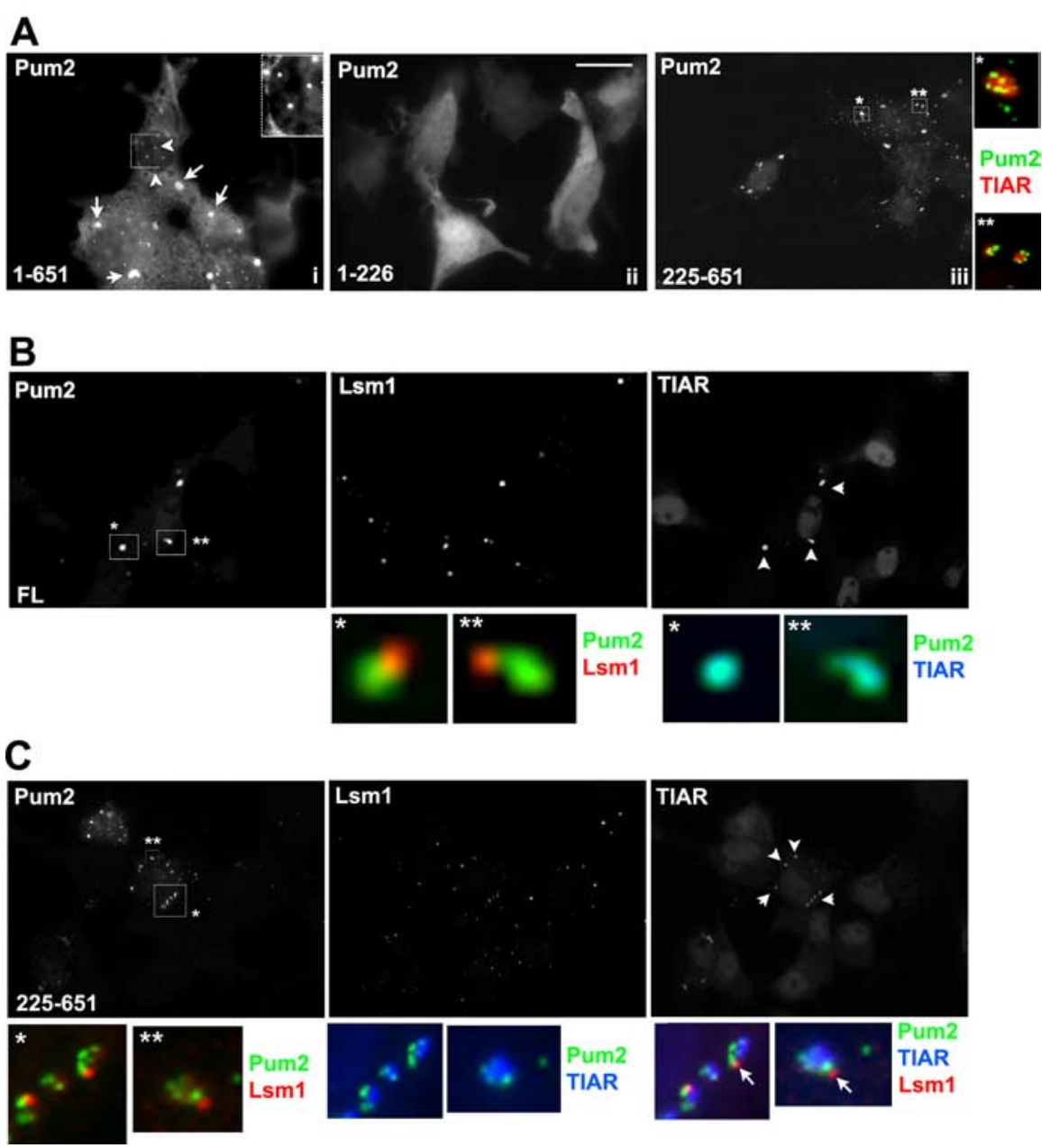

Figure 9. A glutamine-rich region in the $\mathrm{N}$ terminus is responsible for the formation of $\mathrm{SG}$ after overexpression. N-terminal deletion mutants (see scheme) of Pum2-EYFP were transiently transfected into HeLa cells. $\boldsymbol{A}$, The $\mathrm{N}$ terminus lacking the QRR in the N terminus (1-226; Ai) does not form SGs after overexpression or in the presence of arsenite (data not shown). The portion of the N terminus containing the QRR forms small puncta and causes the formation of TIAR-positive SGs (225-651; Aiii). These small puncta colocalize with the TIAR granules (enlargements marked with asterisks). B, P-bodies detected with an anti-Lsm1 antibody (red) are adjacent to but not overlapping with either overexpressed Pum2 $2_{\mathrm{FL}}$ (green) or TIAR (blue). C, The small granules induced by overexpression of Pum2 $225-651$ (green) do not colocalize with either Lsm1 (red) or TIAR (blue). Arrowheads indicate small Pum2 granules. Arrows indicate Lsm1-positive P-bodies.Scale bar, $10 \mu \mathrm{m}$.

strate that neurons lacking endogenous Pum2 were still capable of forming a stress response, neurons were cotransfected with si-Pum2-1 and the C terminus of Pum2 (Pum2 ${ }_{650-S t o p}$ ) or alternatively, with si-Pum2-1 and GFP. Pum $2_{650-S t o p}$ contains the PHD and is resistant to si-Pum2-1 because this siRNA targets a region in the $\mathrm{N}$ terminus. Cells containing Pum $2_{650-S t o p}$ in addition to si-Pum2-1 were significantly more able to form SGs in response to arsenite treatment when compared with the control experiment in which si-Pum2-1 was cotransfected with GFP (Fig. $11 B$, right graph). This finding further verifies that the RNAi plasmids used for these experiments specifically affected Pum2 expression, because the SG phenotype could be rescued with an RNAi-resistant Pum2 fragment.

\section{Discussion}

Mammalian Pum 2 is expressed in neurons and is a novel member of dendritic stress granules

In this study, we have shown that mammalian Pum 2 is expressed in neurons and represents a novel candidate component of dendritic RNPs (Mallardo et al., 2003). Dendritic expression of Pum2 was dependent on an intact microtubule network because disruption of polarized microtubules led to a reduction in the amount of dendritic staining and a reduction of the punctate staining pattern. Microtubuledependent dendritic localization of RNP components such as Staul and FMRP has been demonstrated (Köhrmann et al., 1999; Antar et al., 2005). Because the previously identified role of Pum2 is that of a translational inhibitor (Wang et al., 2002), it is tempting to speculate that its presence in dendrites includes a role in the translational regulation of localized mRNA (Dahm and Kiebler, 2005). Its punctate, microtubule-associated expression pattern in the dendritic shaft mimics that of RNA-binding proteins known to be part of the RNA transport and translational control machinery. Stau2 is an example of such a protein and has been shown to regulate spine morphogenesis (Goetze et al., 2006). However, like Pum2, it is not found within the spine itself, but localizes in dendrites immediately beneath the shaft of the spine. The exact role of both proteins in this location remains unknown.

Pum2 did not cofractionate with ribosomal subunits in the low-density fractions of a sucrose gradient. This pattern persisted in the presence of cycloheximide and puromycin, demonstrating that it was not associated with ribosomal subunits or polysomes. In contrast, shown here and in previous studies (Thomas et al., 2005), Staul is consistently found in fractions containing ribosomal subunits. This suggests that Pum2, in contrast to Stau1, might be associated with nontranslating mRNA and assist in blocking translational initiation. This behavior is comparable with mammalian Smaug, another RNA binding protein that acts to repress translation (Baez and Boccaccio, 2005). In the same study, Smaug was also found in SGs, further indicating that these two proteins may serve similar roles. Selectivity arises when their target RNA sequences are compared. As opposed to the NRE that Pum 2 binds, Smaug binds the Smaug recognition element (Crucs et al., 2000).

We hypothesized that interfering with protein translation would cause changes in localization of Pum2. To test this, we interfered with translation via the application of puromycin and observed the formation of large aggregates in the soma and dendrites that was reminiscent of SGs found in other cell types (Ked- 
ersha and Anderson, 2002). Additional investigation using antibodies targeting known components of these structures verified this assumption. Although the highest concentration of Pum2-positive SGs was in the soma, their presence in distal dendrites is of interest because it is known that a pool of mRNA critical for synaptic plasticity is localized to this cellular compartment (Steward and Schuman, 2001). Although they share many protein components, it will be interesting to see whether dendritic SGs are of similar composition to those in the soma. Metabolic stress also recruited other proteins involved in dendritic mRNA transport to Pum2-containing SGs. Staul and Btz were found within the SGs formed when Pum2 was overexpressed. Dendritic SGs also contain polyadenylated mRNA, suggesting that these granules are sites of stalled translating mRNA, a hypothesis based on the established role of SGs (Kedersha and Anderson, 2002). These findings are the first indication that, when exposed to stress, components of dendritically localized RNPs are packaged into SGs containing polyadenylated mRNAs.

An obvious question is on which RNAs Pum2 may act as well as bind and/or target to dendritic SGs. One interesting candidate is the mRNA encoding eukaryotic translation elongation factor $1 \mathrm{~A}$ (eEF1A). It has been shown that Pum2 binds to this mRNA (Fox et al., 2005) and it localizes into dendrites in which it displays increased levels of translation during synaptic activity (Tsokas et al., 2005). Because eEF1A is required for peptide chain elongation, this protein is potentially rate limiting for translation. We speculate that Pum2, in dendrites, binds this mRNA and keeps eEF1A protein levels low. In response to synaptic activity, eEF1A undergoes an increase in translation that could be modulated via the release of Pum2 from its mRNA. Drosophila Pum is also known to bind the $3^{\prime}$-UTR of another regulator of translation, eIF4E (Menon et al., 2004). Through interactions with both eEF1A, a regulator of peptide elongation, and eIF-4E, a regulator of translational initiation, it appears that Pum2 could serve as a modulator of translational fidelity.

\section{Pum 2 containing SGs are in dynamic equilibrium} with polysomes

During stress, polysomes and SGs are in a state of dynamic equilibrium (Kedersha et al., 2005). Cycloheximide interferes with translation by blocking peptide elongation and halting ribosomes on translating mRNA (Kedersha et al., 2000). This drug has been used to demonstrate the dynamic nature of SGs in cell lines. After addition of cycloheximide, SGs are no
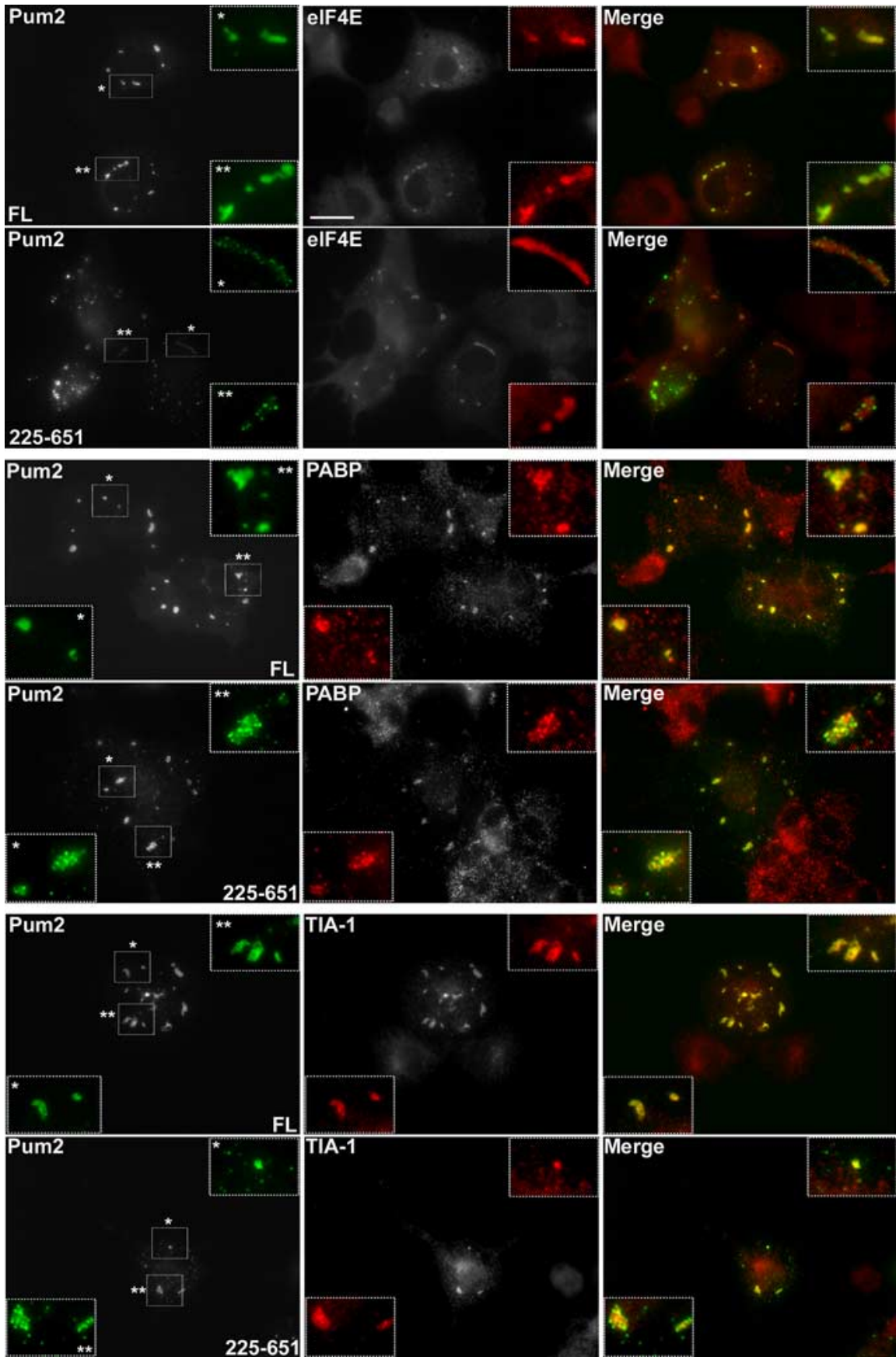

Figure 10. Overexpression of Pum2 recruits additional components of $S G s$. Overexpression of both Pum2 $2_{\mathrm{FL}}$ and the N terminus containing the QRR (Pum2 $225-651$ ) in HeLa cells causes the aggregation of TIA1, elF4E, and PABP in a pattern similar to TIAR. The * and ** symbols represent enlargements in color. Scale bar, $10 \mathrm{~mm}$.

longer visible when cells are stained with antibodies used for SG detection. With polysomes no longer available for recruitment into SGs, any existing granules will dissolve and escape visualization. We demonstrate a similar phenomenon in neuronal SGs. Cycloheximide led to the loss of Pum2-positive SGs in both the soma and dendrites. This was also observed with SGs induced by overexpression of Pum $2_{\mathrm{FL}}$. Conversely, puromycin, by releasing polysomes from translating mRNA, leads to the formation of SGs in the absence of stress (Kedersha et al., 2000).

Arsenite is known to increase the number of P-bodies along with SGs (Kedersha et al., 2005). P-bodies are sites of mRNA 
A
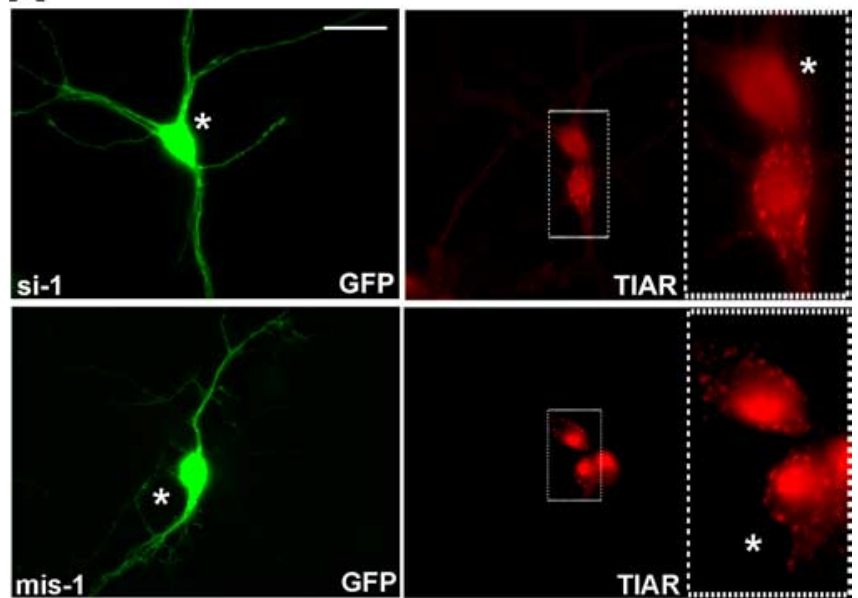

B
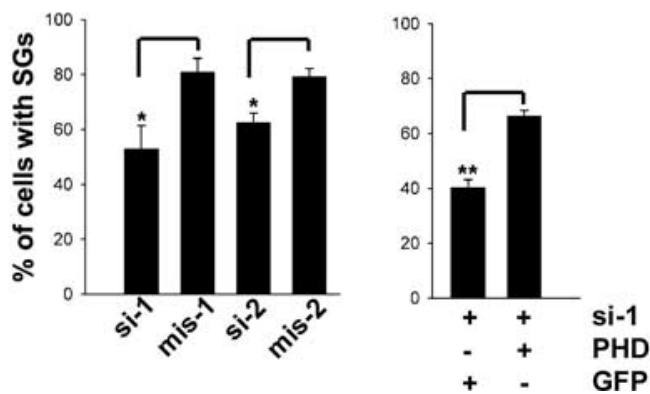

Figure 11. Downregulation of Pum2 with RNAi leads to an impairment of neuronal SG assembly. $\boldsymbol{A}$, Neurons transfected with either the si-Pum2-1 construct (top) or the corresponding mismatch control (mis-Pum2-1, bottom). Neurons expressing si-Pum2-1 (see supplemental Fig. S3 B, C for the effect of these plasmids on Pum2 expression, available at www.jneurosci. org as supplemental material) lack TIAR-positive SGs in the cell body when exposed to $0.5 \mathrm{~mm}$ arsenite $3 \mathrm{~d}$ after transfection. Conversely, neurons expressing mis-Pum2-1 respond to the stress stimuli with the formation of TIAR-positive SGs in the cell soma. Scale bar, $10 \mu \mathrm{m} . \boldsymbol{B}$, The left bar graph displays the quantification of three independent experiments of Pum2 downregulation on SG assembly. With both si-Pum2 plasmids, cells were significantly less likely to form TIAR-positive SGs when exposed to arsenite. The right bar graph depicts a rescue of this effect. Cotransfection with si-Pum2-1 and Pum2 ${ }_{650-\text {-stop }}$ (PHD) led to a complete recovery $(p<$ 0.01 ) of the observed phenotype. Conversely, cotransfection of si-Pum2-1 and GFP yielded the same result as when both siRNA plasmids were transfected alone. ${ }^{*} p<0.05 ;{ }^{* *} p<0.01$. Error bars represent SEM.

decay (Sheth and Parker, 2003), and we have shown that during stress, the number of P-bodies increases in dendrites. This indicates that in the presence of stress, the potential exists for dendritically localized mRNA to be targeted for decay. Although it has been proposed that SGs and P-bodies communicate via molecules such as CPEB (Wilczynska et al., 2005), it remains to be demonstrated that mRNA targeted for decay passes through SGs before delivery to P-bodies. We observed no colocalization of SG and P-body markers under any of our experimental conditions.

\section{A glutamine-rich region in the $\mathrm{N}$ terminus is capable of inducing SG assembly}

Overexpression of the Pum2 QRR induced the formation of small aggregates that recruited known components of SGs such as TIAR, TIA-1, PABP, and eIF4E. Although visibly similar to the smaller P-bodies, Pum2 QRR aggregates were not associated with these structures. Rather, these small aggregates clustered around the periphery of SGs. Similar effects have been reported with the overexpression of a glutamine-rich region of TIA-1. The TIA-1 glutamine-rich domain, similar to that of Pum2, is structurally related to prion protein (Gilks et al., 2004). It has therefore been proposed that TIA-1 prion-like activity is responsible for the initial protein aggregation during stress. This leads to the formation of a scaffold onto which stalled initiation complexes and other proteins associated with SGs can bind (Gilks et al., 2004). Unlike TIA- 1 and TIAR, which are primarily nuclear proteins, Pum2 is found in distal dendrites. Prion-like activity of Pum 2 could therefore mediate the aggregation of nontranslating RNPs into dendritic SGs. What remains to be resolved is the catalytic event that would induce Pum 2 prion-like activity. TIA-1 prion-like behavior is regulated by levels of heat shock protein 70 (HSP70) protein in a complex relationship. High levels of HSP70 reduce or even block aggregation of TIA-1 (Gilks et al., 2004). However, our preliminary data show that overexpression of Pum2 does not induce upregulation or downregulation of HSP70 translation (J. P. Vessey and P. Macchi, unpublished observations).

\section{Downregulation of Pum2 via RNAi interferes with SG formation}

Loss of Pum2 protein led to a moderate, but significant, reduction in cells forming SGs after exposure to stress. The observation of only a moderate reduction could be explained by residual Pum2 expression. We can also not exclude potential compensatory mechanisms of Pum1, because Puml is also expressed in neurons (Vessey and Macchi, unpublished observations). This finding nonetheless offers some indication that Pum 2 is involved in the formation of SGs in neurons and may act to deliver mRNA to these structures. The observed reduction in SG formation was rescued with cotransfection of a siRNA-resistant Pum 2 mRNA. This led to a reversal of the observed phenotype. The $\mathrm{C}$ terminus is capable of inducing the formation of SGs after overexpression. In its presence, SGs formed and TIAR was recruited from the nucleus. This indicates that the molecular pathways required for SG formation remain intact in the absence of Pum 2 and that stability of either TIAR mRNA or protein was not affected by a loss of Pum2.

\section{References}

Antar LN, Dictenberg JB, Plociniak M, Afroz R, Bassell GJ (2005) Localization of FMRP-associated mRNA granules and requirement of microtubules for activity-dependent trafficking in hippocampal neurons. Genes Brain Behav 4:350-359.

Asaoka-Taguchi M, Yamada M, Nakamura A, Hanyu K, Kobayashi S (1999) Maternal Pumilio acts together with Nanos in germline development in Drosophila embryos. Nat Cell Biol 1:431-437.

Baez MV, Boccaccio GL (2005) Mammalian smaug is a translational repressor that forms cytoplasmic foci similar to stress granules. J Biol Chem 280:43131-43140.

Baines RA (2005) Neuronal homeostasis through translational control. Mol Neurobiol 32:113-122.

Brummelkamp TR, Bernards R, Agami R (2002) A system for stable expression of short interfering RNAs in mammalian cells. Science 296:550-553.

Cougot N, Babajko S, Seraphin B (2004) Cytoplasmic foci are sites of mRNA decay in human cells. J Cell Biol 165:31-40.

Crucs S, Chatterjee S, Gavis ER (2000) Overlapping but distinct RNA elements control repression and activation of nanos translation. Mol Cell 5:457-467.

Dahm R, Kiebler M (2005) Cell biology: silenced RNA on the move. Nature 438:432-435.

de Moor CH, Meijer H, Lissenden S (2005) Mechanisms of translational control by the $3^{\prime}$ UTR in development and differentiation. Semin Cell Dev Biol 16:49-58.

Dubnau J, Chiang AS, Grady L, Barditch J, Gossweiler S, McNeil J, Smith P, Buldoc F, Scott R, Certa U, Broger C, Tully T (2003) The staufen/pumilio pathway is involved in Drosophila long-term memory. Curr Biol $13: 286-296$. 
Fox M, Urano J, Reijo Pera RA (2005) Identification and characterization of RNA sequences to which human PUMILIO-2 (PUM2) and deleted in Azoospermia-like (DAZL) bind. Genomics 85:92-105.

Gilks N, Kedersha N, Ayodele M, Shen L, Stoecklin G, Dember LM, Anderson $\mathrm{P}$ (2004) Stress granule assembly is mediated by prion-like aggregation of TIA-1. Mol Biol Cell 15:5383-5398.

Goetze B, Grunewald B, Baldassa S, Kiebler M (2004) Chemically controlled formation of a DNA/calcium phosphate coprecipitate: application for transfection of mature hippocampal neurons. J Neurobiol 60:517-525.

Goetze B, Tuebing F, Xie Y, Dorostkar MM, Thomas S, Pehl U, Boehm S, Macchi P, Kiebler MA (2006) The brain-specific double-stranded RNAbinding protein Staufen2 is required for dendritic spine morphogenesis. J Cell Biol 172:221-231.

Ingelfinger D, Arndt-Jovin DJ, Lührmann R, Achsel T (2002) The human Lsm1-7 proteins colocalize with the mRNA-degrading enzymes Dcp 1/2 and Xrnl in distinct cytoplasmic foci. RNA 8:1489-1501.

Kedersha N, Anderson P (2002) Stress granules: sites of mRNA triage that regulate mRNA stability and translatability. Biochem Soc Trans 30:963-969.

Kedersha N, Gupta M, Li W, Miller I, Anderson P (1999) RNA-binding proteins TIA-1 and TIAR link the phosphorylation of eIF-2 alpha to the assembly of mammalian stress granules. J Cell Biol 147:1431-1442.

Kedersha N, Cho MR, Li W, Yacono PW, Chen S, Gilks N, Golan DE, Anderson P (2000) Dynamic shuttling of TIA-1 accompanies the recruitment of mRNA to mammalian stress granules. J Cell Biol 151:1257-1268.

Kedersha N, Chen S, Gilks N, Li W, Miller IJ, Stahl J, Anderson P (2002) Evidence that ternary complex (eIF2-GTP-tRNA(i)(Met))-deficient preinitiation complexes are core constituents of mammalian stress granules. Mol Biol Cell 13:195-210.

Kedersha N, Stoecklin G, Ayodele M, Yacono P, Lykke-Andersen J, Fitzler MJ, Scheuner D, Kaufman RJ, Golan DE, Anderson P (2005) Stress granules and processing bodies are dynamically linked sites of mRNP remodeling. J Cell Biol 169:871-884.

Kim SH, Dong WK, Weiler IJ, Greenough WT (2006) Fragile X mental retardation protein shifts between polyribosomes and stress granules after neuronal injury by arsenite stress or in vivo hippocampal electrode insertion. J Neurosci 26:2413-2418.

Kim YK, Furic L, Desgroseillers L, Maquat LE (2005) Mammalian Staufen1 recruits Upf1 to specific mRNA $3^{\prime} \mathrm{UTR} s$ so as to elicit mRNA decay. Cell 120:195-208.

Kimball SR, Horetsky RL, Ron D, Jefferson LS, Harding HP (2003) Mammalian stress granules represent sites of accumulation of stalled translation initiation complexes. Am J Physiol Cell Physiol 284:C273-C284.

Köhrmann M, Luo M, Kaether C, DesGroseillers L, Dotti CG, Kiebler MA (1999) Microtubule-dependent recruitment of Staufen-green fluorescent protein into large RNA-containing granules and subsequent dendritic transport in living hippocampal neurons. Mol Biol Cell 10:2945-2953.

Liu J, Valencia-Sanchez MA, Hannon GJ, Parker R (2005) MicroRNAdependent localization of targeted mRNAs to mammalian P-bodies. Nat Cell Biol 7:719-723.

Lykke-Andersen J (2002) Identification of a human decapping complex associated with hUpf proteins in nonsense-mediated decay. Mol Cell Biol 22:8114-8121.

Macchi P, Kroening S, Palacios IM, Baldassa S, Grunewald B, Ambrosino C, Goetze B, Lupas A, St Johnston D, Kiebler M (2003) Barentsz, a new component of the Staufen-containing ribonucleoprotein particles in mammalian cells, interacts with Staufen in an RNA-dependent manner. J Neurosci 23:5778-5788.

Macchi P, Brownawell AM, Grunewald B, DesGroseillers L, Macara IG, Kiebler MA (2004) The brain-specific double-stranded RNA-binding protein Staufen2: nucleolar accumulation and isoform-specific exportin-5dependent export. J Biol Chem 279:31440-31444.

Mallardo M, Deitinghoff A, Muller J, Goetze B, Macchi P, Peters C, Kiebler MA (2003) Isolation and characterization of Staufen-containing ribonucleoprotein particles from rat brain. Proc Natl Acad Sci USA 100:2100-2105.

Mazroui R, Huot ME, Tremblay S, Filion C, Labelle Y, Khandjian EW (2002) Trapping of messenger RNA by Fragile X Mental Retardation protein into cytoplasmic granules induces translation repression. Hum Mol Genet 11:3007-3017.
Mee CJ, Pym EC, Moffat KG, Baines RA (2004) Regulation of neuronal excitability through pumilio-dependent control of a sodium channel gene. J Neurosci 24:8695-8703.

Menon KP, Sanyal S, Habara Y, Sanchez R, Wharton RP, Ramaswami M, Zinn K (2004) The translational repressor Pumilio regulates presynaptic morphology and controls postsynaptic accumulation of translation factor eIF-4E. Neuron 44:663-676.

Micklem DR (1995) mRNA localisation during development. Dev Biol 172:377-395.

Monshausen M, Putz U, Rehbein M, Schweizer M, DesGroseillers L, Kuhl D, Richter D, Kindler S (2001) Two rat brain staufen isoforms differentially bind RNA. J Neurochem 76:155-165.

Murata Y, Wharton RP (1995) Binding of pumilio to maternal hunchback mRNA is required for posterior patterning in Drosophila embryos. Cell 80:747-756.

Nakahata S, Katsu Y, Mita K, Inoue K, Nagahama Y, Yamashita M (2001) Biochemical identification of Xenopus Pumilio as a sequence-specific cyclin B1 mRNA-binding protein that physically interacts with a Nanos homolog, Xcat-2, and a cytoplasmic polyadenylation element-binding protein. J Biol Chem 276:20945-20953.

Nakahata S, Kotani T, Mita K, Kawasaki T, Katsu Y, Nagahama Y, Yamashita M (2003) Involvement of Xenopus Pumilio in the translational regulation that is specific to cyclin B1 mRNA during oocyte maturation. Mech Dev 120:865-880.

Palacios IM, Gatfield D, St Johnston D, Izaurralde E (2004) An eIF4AIIIcontaining complex required for mRNA localization and nonsensemediated mRNA decay. Nature 427:753-757.

Parisi M, Lin H (2000) Translational repression: a duet of Nanos and $\mathrm{Pu}$ milio. Curr Biol 10:R81-R83.

Schweers BA, Walters KJ, Stern M (2002) The Drosophila melanogaster translational repressor pumilio regulates neuronal excitability. Genetics 161:1177-1185.

Sheth U, Parker R (2003) Decapping and decay of messenger RNA occur in cytoplasmic processing bodies. Science 300:805-808.

Spassov DS, Jurecic R (2002) Cloning and comparative sequence analysis of PUM1 and PUM2 genes, human members of the Pumilio family of RNAbinding proteins. Gene 299:195-204.

Steward O, Schuman EM (2001) Protein synthesis at synaptic sites on dendrites. Annu Rev Neurosci 24:299-325.

Tang SJ, Meulemans D, Vazquez L, Colaco N, Schuman E (2001) A role for a rat homolog of staufen in the transport of RNA to neuronal dendrites. Neuron 32:463-475.

Thomas MG, Tosar LJ, Loschi M, Pasquini JM, Correale J, Kindler S, Boccaccio GL (2005) Staufen recruitment into stress granules does not affect early mRNA transport in oligodendrocytes. Mol Biol Cell 16:405-420.

Tsokas P, Grace EA, Chan P, Ma T, Sealfon SC, Iyengar R, Landau EM, Blitzer $\mathrm{RD}$ (2005) Local protein synthesis mediates a rapid increase in dendritic elongation factor $1 \mathrm{~A}$ after induction of late long-term potentiation. J Neurosci 25:5833-5843.

Wang X, McLachlan J, Zamore PD, Hall TM (2002) Modular recognition of RNA by a human pumilio-homology domain. Cell 110:501-512.

Wharton RP, Struhl G (1991) RNA regulatory elements mediate control of Drosophila body pattern by the posterior morphogen nanos. Cell 67:955-967.

White EK, Moore-Jarrett T, Ruley HE (2001) PUM2, a novel murine puf protein, and its consensus RNA-binding site. RNA 7:1855-1866.

Wickens M, Bernstein DS, Kimble J, Parker R (2002) A PUF family portrait: 3'UTR regulation as a way of life. Trends Genet 18:150-157.

Wilczynska A, Aigueperse C, Kress M, Dautry F, Weil D (2005) The translational regulator CPEB1 provides a link between $\mathrm{dcp} 1$ bodies and stress granules. J Cell Sci 118:981-992.

Wu L, Wells D, Tay J, Mendis D, Abbott MA, Barnitt A, Quinlan E, Heynen A, Fallon JR, Richter JD (1998) CPEB-mediated cytoplasmic polyadenylation and the regulation of experience-dependent translation of alphaCaMKII mRNA at synapses. Neuron 21:1129-1139.

Ye B, Petritsch C, Clark IE, Gavis ER, Jan LY, Jan YN (2004) Nanos and Pumilio are essential for dendrite morphogenesis in Drosophila peripheral neurons. Curr Biol 14:314-321.

Zamore PD, Williamson JR, Lehmann R (1997) The Pumilio protein binds RNA through a conserved domain that defines a new class of RNAbinding proteins. RNA 3:1421-1433. 